JPDN ISSN 2579-6461 (Online) ISSN 2460-6324 (Print)

Jurnal Pendidikan Dasar Nusantara

Volume $6 \mid$ Nomor $1 \mid$ Juli $2020 \mid$

DOI: https://doi.org/10.29407/jpdn.v4i2.xxxxx

\title{
IMPLEMENTASI PERKULIAHAN DARING MATAKULIAH PENDIDIKAN LABORATORIUM IPA PADA MASA PANDEMI
}

\author{
Farida Nurlaila Zunaidah ${ }^{1}$ \\ Farida@unpkediri.ac.id \\ PGSD, FKIP, Universitas Nusantara PGRI Kediri ${ }^{1}$ \\ No Handphone: 085655654555
}

\begin{abstract}
Abstrak: Penelitian ini dilakukan dengan tujuan untuk menggambarkan implementasi perkuliahan daring matakuliah Pendidikan Laboratorium IPA pada mahasiswa PGSD semester 4 selama masa pandemi covid-19. Metode dalam penelitian ini adalah kualitatif deskriptif. Data hasil penelitian dideskripsikan dalam bentuk uraian kata-kata yang menggambarkan tahapan pelaksaan perkuliahan daring. Hasil dari penelitian ini adalah perkuliahan daring Pendidikan Laboratorium IPA terdiri atas tiga tahap yaitu tahap persiapan, tahap pelaksanaan, dan tahap pemberian tugas terstruktur berupa laporan hasil kegiatan praktikum.
\end{abstract}

Kata kunci: implementasi perkuliahan daring, matakuliah Pendidikan Laboratorium IPA, masa pandemi

\section{IMPLEMENTATION ONLINE LECTURES OF PENDIDIKAN LABORATORIUM IPA COURSE ON PANDEMIC PERIOD}

\begin{abstract}
This research was conducted with the aim to describe the implementation of online lectures on Pendidikan Laboratorium IPA courses at the 4th semester of students college PGSD during the covid-19 pandemic. The method in this research is descriptive qualitative. The research data are described in the form of words that describe the stages of conducting online lectures. The results of this study are online lectures on Pendidikan Laboratoriun IPA consisting of three stages, namely the preparatory stage, the implementation stage, and the structured assignment stage in the form of reports on the results of practical activities.
\end{abstract}

Keywords: implementation of online lecturer, Pendidikan Laboratorium IPA course, pandemic period

\section{PENDAHULUAN}

Seperti yang kita ketahui bersama, mulai bulan maret 2020 pemerintah negara Indonesia mulai mencanangkan untuk siaga covid-19. Hal tersebut berkelanjutan 
Farida. Implementasi Perkuliahan daring matakuliah.....

sampai bulan april 2020. Mulai pada saat itu, semua aspek mulai merasakan dampak menyebarnya pandemic covid-19. Pemerinta Indonesia mulai mencanangkan program WFH (work from home) sebagai upaya social distancing untuk menekan penyebaran covid-19 bagi pekerja yang bisa mengerjakan semua pekerjaannya dirumah. Hal ini berdampak pula pada aspek pendidikan. Selain para pengajar harus WFH, para peserta didik juga harus melaksanakan SFH (study from home). Pada perguruan tinggi WFH dan SFH memunculkan tantangan baru mengenai kesiapan dosen dan mahasiswa dalam melakukan perkuliahan daring yang mewajibkan semua pekerjaan harus berbasis teknologi online (Khasanah et al., 2020).

Pendidikan Laboratorium IPA merupakan salah satu mata kuliah pada Prodi PGSD Universitas Nusantara PGRI Kediri yang wajib melaksanakan perkuliahan daring. Tantangan perkuliahan daring pada matakuliah Pendidikan Laboratorium IPA adalah penggunaan metode praktikum. Metode praktikum mewajibkan semua mahasiswa untuk melakukan praktik dalam menemukan sebab suatu masalah, membuktikan kebenaran sebuah teori dan menyimpulkannya (Saida et al., 2018). Dalam pelaksanaan perkuliahan metode praktikum masih membutuhkan bimbingan dan arahan dari dosen selama kegiatan praktikum berlangsung (Saida et al., 2018). Tentunya jika metode praktikum dilaksanakan secara daring maka akan berbeda pelaksanaannya dengan perkuliahan tatap muka.

Menyikapi permasalahan tersebut, perlu adanya inovasi dalam sebuah pembelajaran daring. Khususnya pada matakuliah berbasis praktik yang mengaruskan mahasiswa melakukan sebuah kegiatan praktikum. Implementasi perkuliahan daring pun dituntut agar tetap sesuai dengan kesepakatan pada kontrak kuliah. Perbedaan perkuliahan tatap muka dan daring yaitu pada implementasi perkuliahan daring yang mengharuskan pemanfaatan media online sebagai sarana perkuliahan (Jamaluddin et al., 2020). Inovasi, tanggu jawab serta kerjasama antara mahasiswa dan dosen adalah kunci utama dalam kelancararan implentasi perkuliahan daring Pendidikan laboratorium IPA. Dan pada akhirnya implementasi perkuliahan online akan berjalan lancar dan tetap mencapai indicator yang diharapkan sesuai yang sudah disepakati pada kontrak perkuliahan

\section{METODE}




\section{Farida. Implementasi Perkuliahan daring matakuliah.....}

Penelitian ini menggunakan metode kualitatif deskriptif pada penjabaran analisisnya. Penjabaran yang dilakukan terkait implementasi perkuliahan Pendidikan Laboratorium IPA pada masa pandemi. Populasi dalam penelitian ini adalah mahasiswa Prodi PGSD semester 4 Universitas Nusantara PGRI Kediri. Sampel berasal dari 2 kelas yaitu kelas 2C dan 2D sebanyak 71 mahasiswa. Prosedur pelaksanan penelitian sesuai dengan jadwal implementasi perkuliahan. Tahapan dalam implementasi berupa tahapan awal yang berisikan persiapan perkuliahan daring, selanjutnya tahapan inti yakni pelaksanaan kegiatan parktikum mandiri dan tahapan yang terakhir yakni pemberian tugas tersetruktur berupa laporan hasil parktikum.

Alat dan bahan dalam penelitian ini berupa alat dan bahan yang dipergunakan dalam proses praktikum mandiri. Alat dan bahan akan berbeda disetiap kegiatan praktikum. Selain itu ada pendukung lainnya yaitu media online yang dipergunakan dalam proses perkuliahan daring. Instrument dalam penelitian ini berupa buku petunjuk praktikum dan pedoman lembar penilaian untuk menilai laporan hasil kegiatan praktikum. Buku petunjuk praktikum bersisi 14 kegiatan praktikum yang mengandung unsur praktik IPA (Fisika-Biologi). Sedangkan pedoman penilaian berupa sitematika penilaian terstruktur dan terdapat point disetiap bagiannya. Teknik analisis data berupa analisis deskriptif berupa penjabaran dalam bentuk bahasa terkait implementasi perkuliahan daring Pendidikan Laboratorium IPA.

Bagian-bagian petunjuk praktikum perkegiatan terdiri atas kegiatan keberapa, judul praktikum, tujuan praktikum, pendahuluan (dasar teori kegiatan praktikum), alat dan bahan praktikum, prosedur kerja praktikum, dan yang terakhir adalah pertanyaan diskusi terkait kegiatan yang telah dilakukan. Sedangkan bagian-bagian dari sistematika penilaian laporan hasil kegiatan praktikum terdiri atas identitas laporan, sistematika laporan dan bagian utama teks laporan.

\section{HASIL}

A. Tahapan Persiapan Daring

Persiapan daring dimulai dengan mempersiapkan video pembelajaran yang terdiri dari video penjelasan persiapan alat dan bahan serta petunjuk prosedur kerja 
Farida. Implementasi Perkuliahan daring matakuliah.....

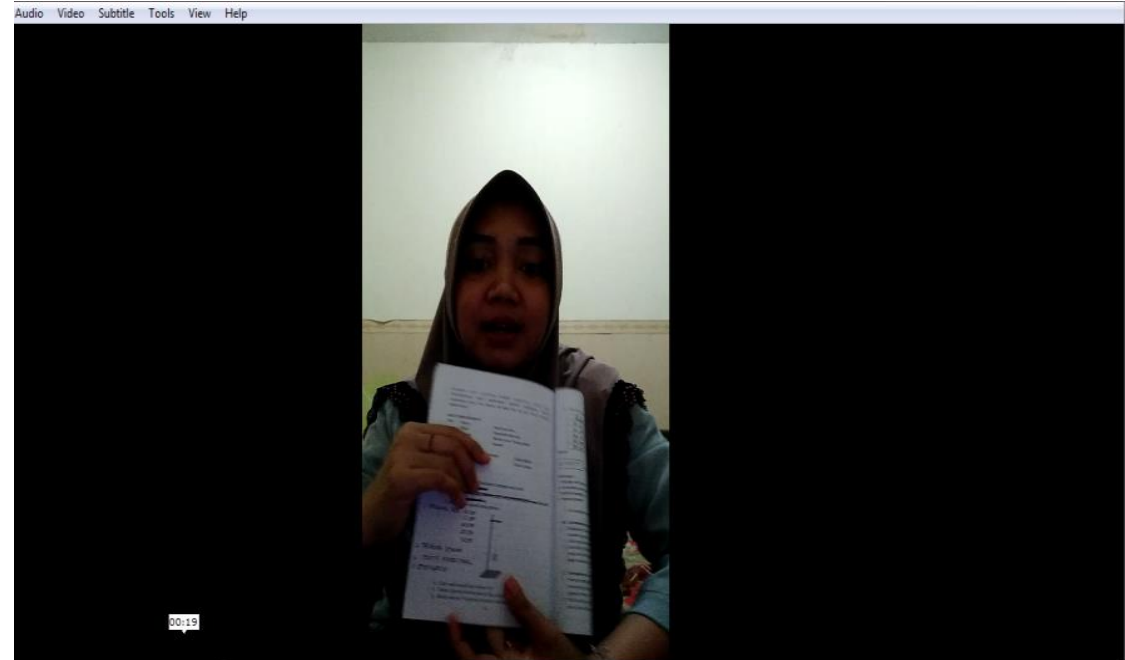

Gambar 1. Video informasi penegarasan alat dan bahan

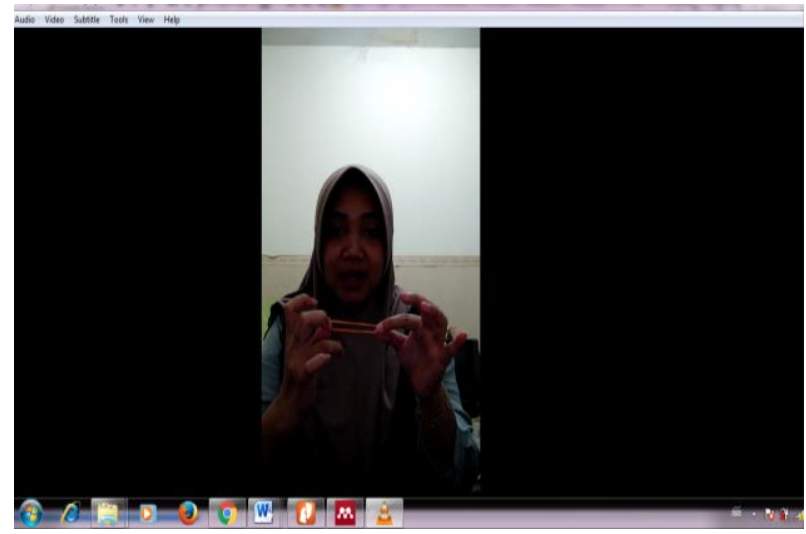

Gambar 2. Video contoh prosedur kerja

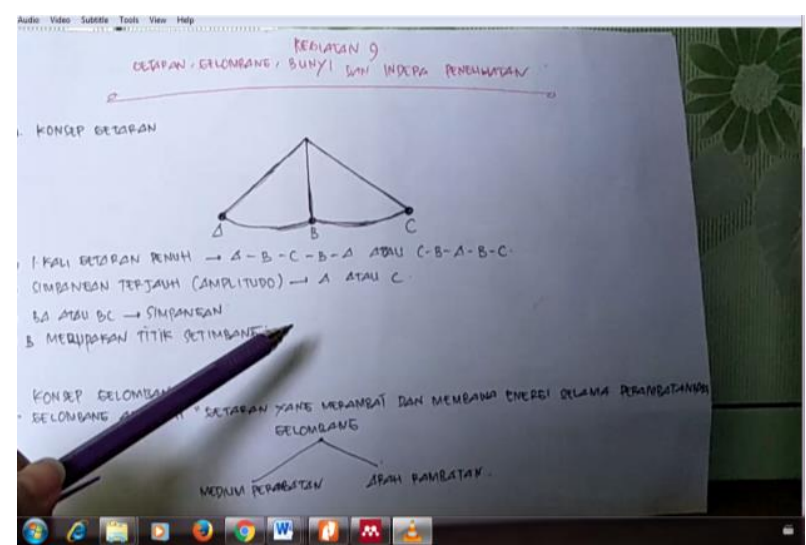

Gambar 3. Video penyampaian materi kegiatan praktikum

B. Tahapan Pelaksanaan Daring

Pelaksanaan daring dimulai dari memberikan presensi kepada mahasiswa, menginformasikan untuk mengumpulkan laporan, pemberian link pengumpulan bukti kegiatan praktikum, memberikan soal diskusi, memberikan tanggapan 
Farida. Implementasi Perkuliahan daring matakuliah.....

mahasiswa terhadap jawaban diskusi, menyimpulkan kegiatan praktikum dan menutup kegiatan praktikum. Berikut gambaran kegiatan praktikum tersebut.

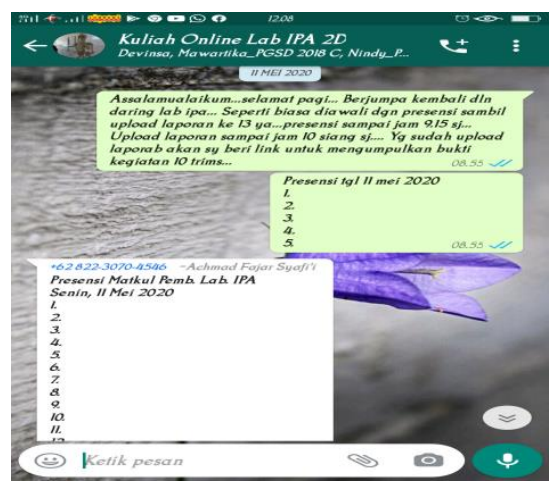

Gambar 4. Melakukan presensi dan menginformasikan pengumpulan laporan praktikum minggu sebelumnya kepada mahasiswa

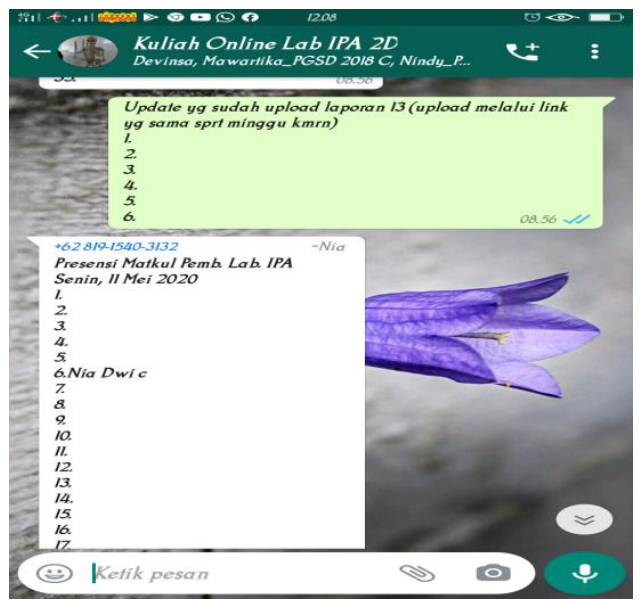

Gambar 5. Memantau pengumpulan laporan melalui link google drive yang sudah dishare sebelumnya

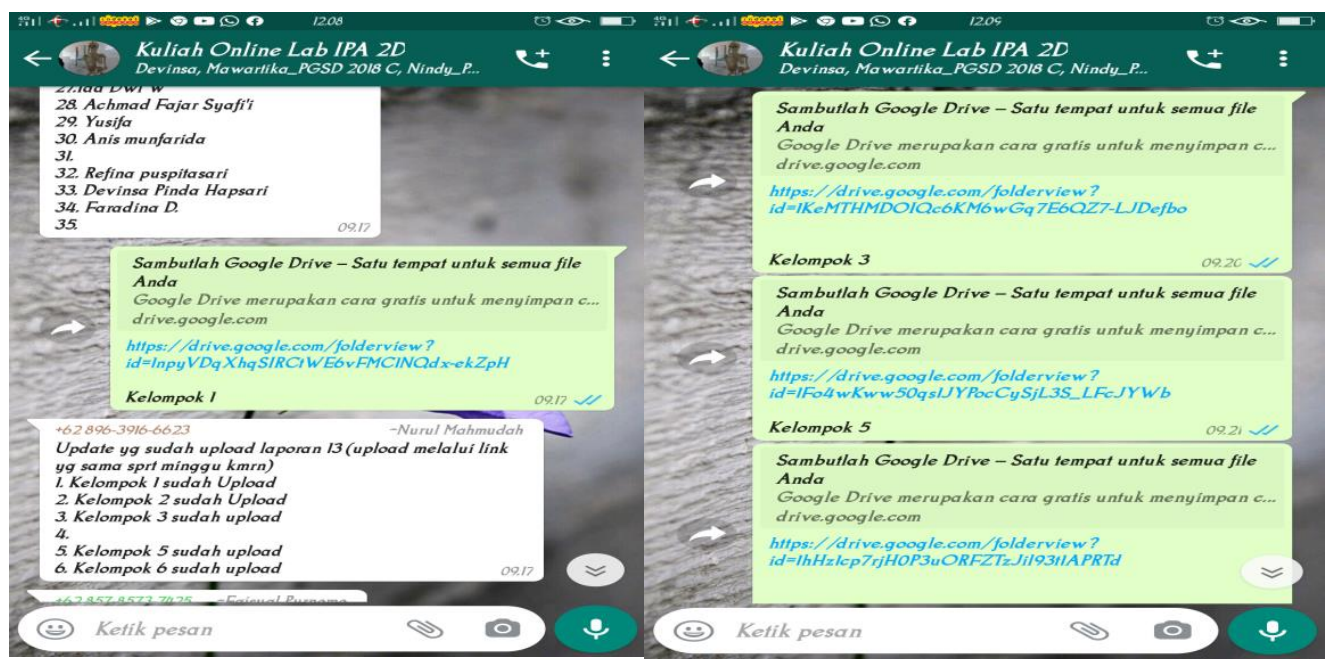


Farida. Implementasi Perkuliahan daring matakuliah.....

Gambar 6. Memantau presensi dan memberikan link google drive untuk mengumpulkan bukti praktikum bagi yang sudah mengumpulkan laporan

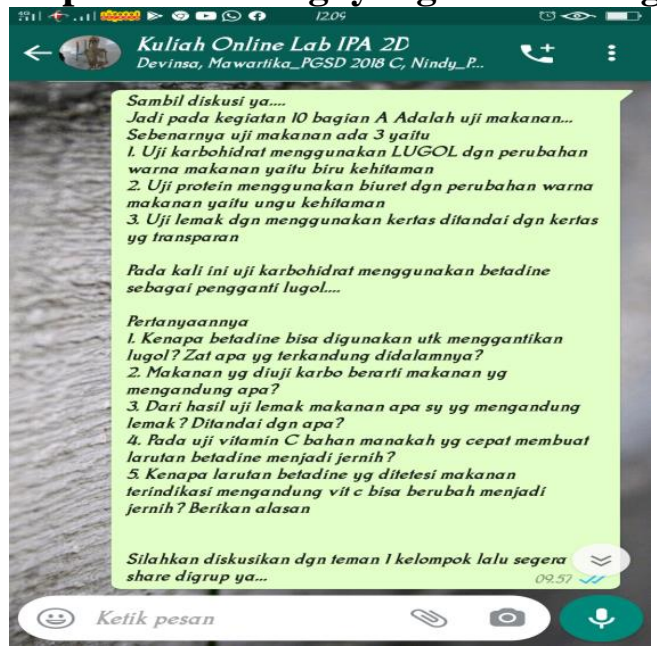

Gambar 7. Memberikan pertanyaan-pertanyaan sebagai bahan diskusi

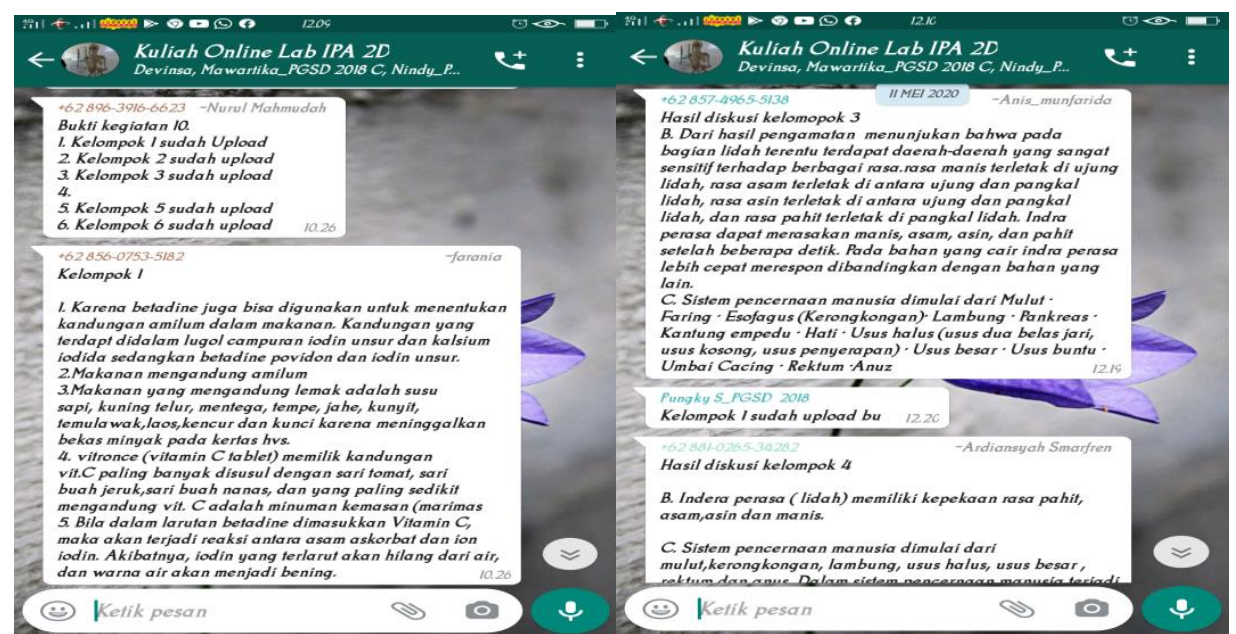

Gambar 8. Memantau kelompok yang sudah mengumpulkan bukti praktikum dan memantau tanggapan mahasiswa terkait pertanyaan diskusi

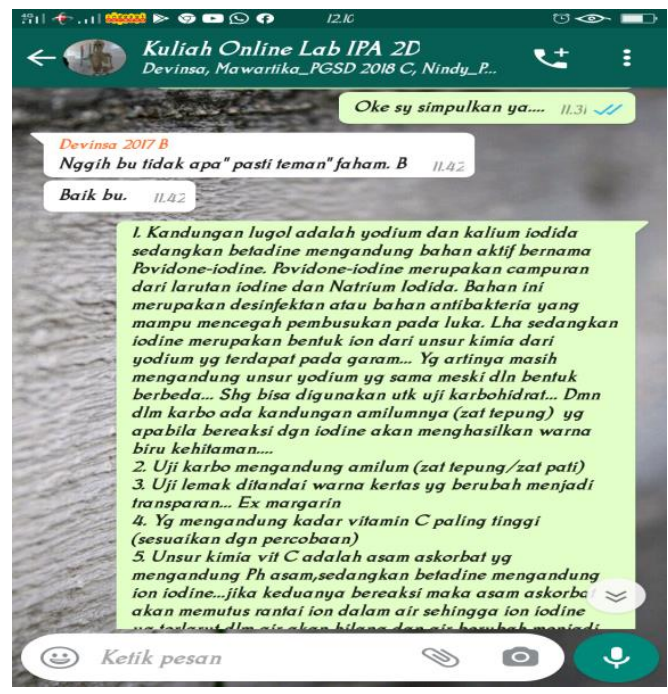


Farida. Implementasi Perkuliahan daring matakuliah.....

Gambar 9. Menanggapi jawaban diskusi dan memberikan penguatan

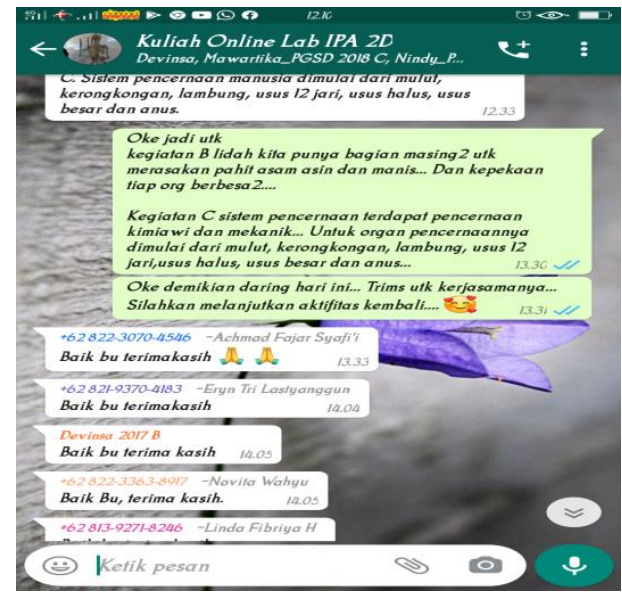

Gambar 10. Memberikan penguatan dan kesimpulan dilanjutkan dengan menutup perkuliahan daring

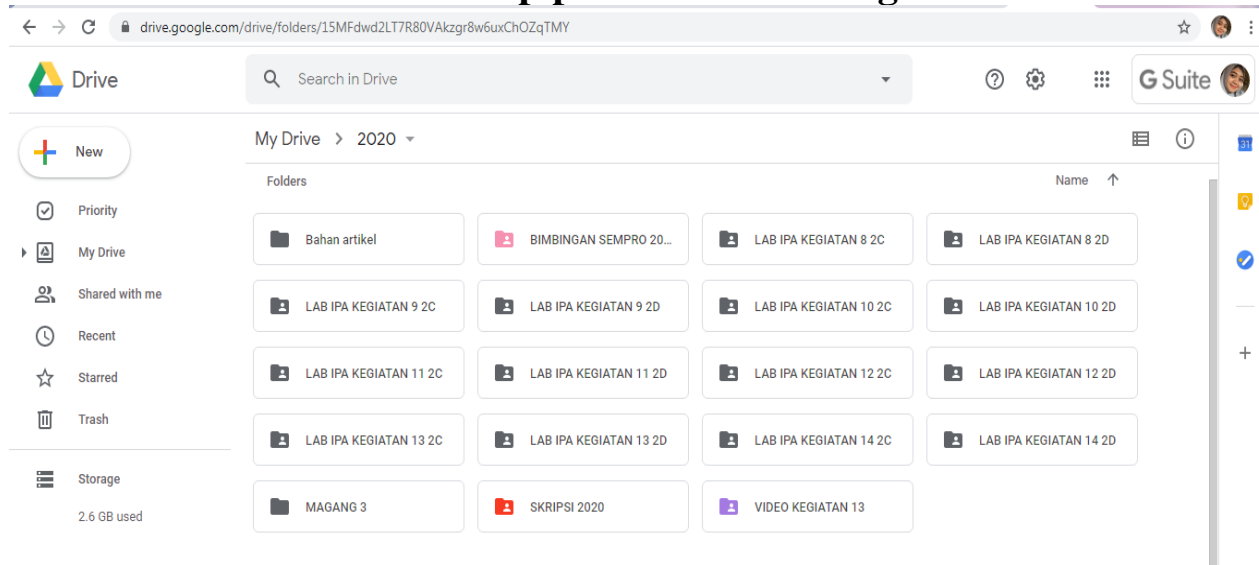

Gambar 11. Link google drive sebagai sarana pengumpulan laporan dan bukti kegiatan praktikum

Tabel 1. Sarana media online dan kegunaannya

\begin{tabular}{|c|c|l|}
\hline No & Media Online & \multicolumn{1}{|c|}{ Kegunaan } \\
\hline 1 & $\begin{array}{c}\text { WAG (Whatsapp } \\
\text { Grup) }\end{array}$ & $\begin{array}{l}\text { WAG dipergunakan untuk membagikan video penguatan } \\
\text { alat bahan serta prosedur kerja praktikum. Selain itu } \\
\text { sebagai sarana untuk berdiskusi, memberikan tanggapan } \\
\text { dan menjawab pertanyaan mahasiswa ketika perkuliahan } \\
\text { online berlangsung. }\end{array}$ \\
\hline & Video & $\begin{array}{l}\text { Berupa video petunjuk alat dan bahan yang akan } \\
\text { dipergunakan untuk praktikum dan video gambaran } \\
\text { prosedur kerja praktikum. }\end{array}$ \\
\hline Google drive & $\begin{array}{l}\text { Digunakan untuk mengumpulkan bukti kegiatan } \\
\text { praktikum dan laporan hasil kegiatan praktikum }\end{array}$ \\
\hline
\end{tabular}

C. Tahapan Pemberian Tugas Terstruktur 
Farida. Implementasi Perkuliahan daring matakuliah.....

Pemberian tugas terstruktur betupa laporan hasil kegiatan praktikum yang sudah dilakukan. Tugas sudah disesuaikan dengan kesepakatan pada saat kontrak perkuliahan. Laporan wajib dikumpulkan 1 minggu sesudah praktikum berlangsung atau minggu berikutnya ketika jadwal perkuliahan online berlangsung. Laporan akan dinilai menurut pedoman penilaian sistematika penulisan laporan.

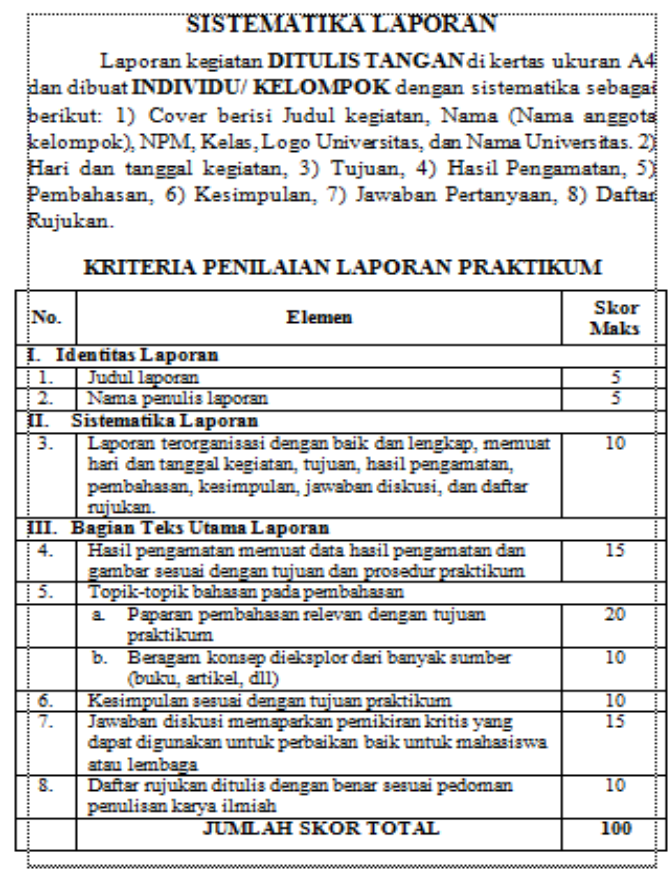

\section{Gambar 12. Sitematika laporan dan sistematika penilaian laporan}

\section{PEMBAHASAN}

\section{A. Tahap Persiapan Perkuliahan Daring}

Sebelum memulai perkuliahan daring, 9 hari sebelumnya dosen membuat video penjelasan mengenai alat bahan yang digunakan praktikum serta prosedur kerjanya. Matakuliah Pendidikan Laboratorim IPA memang memiliki buku petunjuk praktikum dan setiap mahasiswa wajib memilikinya, namun perlu adanya penguatan lagi agar mahasiswa lebih memahami. Ketika perkuliahan tatap muka setiap akhir pertemuan kegiatan perkuliahan, dosen selalu mengingatkan alat, bahan serta prosedur kerja untuk kegiatan praktikum selanjutnya atau untuk minggu depannya. Tujuan pembuatan video juga sama untuk mengingatkan dan memahamkan mahasiswa pada alat, bahan dan prosedur kerja pada kegiatan praktikum berikutnya. 
Farida. Implementasi Perkuliahan daring matakuliah......

Penggunaan media video dalam mendukung sebuah konsep praktik sangat bermanfaat pada pemahaman peserta didik (Iwantara et al., 2014). Pada matakuliah ini memang membutuhkan pemahaman yang mendalam terhadap kerja praktikum sehingga tidak terjadi kesalahan dalam melaksanakan praktikum. Pada penelitian Iwantara et al. (2014) menunjukkan bahwa dengan adanya bantuan media video lebih mempermudah peserta didik dalam memahami dasar teori kegiatan yang akan dipraktikumkan, sehingga dalam melaksanakan praktikum peserta didik juga akan lebih mudah memahami prosedur kerja praktikum.

Konsep teori IPA memang sangat kompleks, sehingga perlu media tertentu salah satunya video untuk mendukung peserta didik dalam memahami konsep teori yang ada (Safrida, 2018). Pemahaman konsep yang didapat mahasiswa akan menjadi pendukung untuk mempermudah melakukan kegiatan praktikum (Primavera \& Iwan Permana Suwarna, 2014). Video mengenai pemahaman alat, bahan dan petunjuk kerja praktikum yang sudah dibuat kemudian dishare melalui WAG masing-masing kelas. Setelah semua kelompok memahami video tersebut, setiap kelompok mulai membagi tugas praktikum pada masing-masing anggota kelompok. Masing-masing tugas praktikum yang diberikan langsung bisa dipraktikkan dirumah masing-masing. Apabila mahasiswa mengalami kendala selama praktikum mandiri, mahasiswa bisa bertanya melalui wag grup yang ada guna diberikan solusi oleh dosen dan sesama temannya. Selain itu dengan sebagai alternative solusi bagi kelompok lain jika mengalami masalah yang sama.

\section{B. Tahap Pelaksanaan Perkuliahan Daring}

Setelah video mengenai alat, bahan dan prosedur kerja dishare melalui grup WAG, mahasiswa bisa langsung mengerjakan praktikum mandiri tanpa menunggu jadwal perkuliahan daring berlangsung. Sehingga ketika jadwal perkuliahan daring berlangsung, tiap kelompok tinggal upload bukti kegiatan praktikum yang telah dilakukan melalui link google drive yang sudah diberikan oleh dosen. Pada saat jadwal perkuliahan, dosen memandu melalui WAG. Dosen mengawali perkuliahan dengan mengadakan presensi mahasiswa. Sesuai kesepakatan, presensi hanya dilakukan selama 10 menit jika melebihi waktu yang ditentukan maka mahasiswa dianggap tidak mengikuti perkuliahan meskipun mahasiswa tersebut tetap melakukan presensi. Dosen juga mengingatkan mahasiswa untuk mengumpulkan laporan praktikum melalui link google drive yang sama untuk mengumpulkan bukti praktikum kegiatan minggu yang 
Farida. Implementasi Perkuliahan daring matakuliah.....

lalu. Bagi kelompok yang sudah mengumpulkan laporan praktikum maka akan diberi link google drive untuk mengumpulkan bukti kegiatan praktikum yang baru.

Pemilihan google drive sebagai sarana untuk mengumpulkan bukti praktikum dan laporan kegiatan hasil praktikum adalah untuk mempermudah dosen dalam memonitoring kegiatan praktikum yang sudah dilakukan oleh mahasiswa. Bukti kegiatan praktikum berupa gampar (jpg) dan video (mp4). Google drive merupakan salah satu pilihan media online untuk menyimpan data dengan aman serta memiliki kapasitas ruang penyimpanan yang besar (Kompas, 2014). Selanjutnya dosen memberikan pertanyaan terkait kegiatan praktikum yang sudah dilakukan dan didiskusikan dengan teman teman satu kelompok. Pertanyaaan berupa diskusi terstruktur terkait setiap bagian dari kegiatan praktikum yang telah dilakukan merupakan salah satu cara untuk menstimulus keaktifan mahasiswa (Suja \& Muderawan, 2003). Pada perkuliahan daring agar mahasiswa aktif berdiskusi pada WAG. Jawaban diskusi lalu dishare oleh masing-masing perwakilan kelompok. selama proses diskusi dosen memberikan tanggapan, jawaban dan meluruskan hasil diskusi agar mahasiswa tidak miskonsepsi terhadap bahan diskusi.

Pemilihan platform WAG sebagai sarana komunikasi dan diskusi karena dinilai sebagai media online yang paling mudah untuk digunakan. Selain itu WAG dapat dijangkau oleh semua kalangan. Namun WAG memiliki kelemahan yakni jika kelas daring yang diajar pasif maka akan lama dalam memberikan umpan balik dalam sebuah diskusi dan perlu diberi umpan balik agar kelas tersebut dapat memberikan respon (Naserly, 2020). Sebenarnya selain menggunakan WAG pernah dicoba untuk menggunakan aplikasi zoom meeting ketika jadwal perkuliahan daring berlangsung. Namun pada praktiknya banyak kendala sinyal dari para mahasiswa. Kendala sinyal pada penggunakan zoom meeting dapat berasal dari penggunaan hospot pribadi yang bersumber dari handphone, sehingga tergantung dari sinyal handphone masing-masing (Naserly, 2020).

Setelah kegiatan diskusi selesai serta semua kelompok sudah mengupload laporan dan bukti kegiatan praktikum, dosen memberikan penguatan berupa kesimpulan hasil diskusi terkait kegiatan praktikum tersebut. Terakhir dosen menutup perkuliahan daring dan tidak lupa dosen mengingatkan kembali kegiatan praktikum yang akan dilakukan serta segera mengupload video penguatan alat, bahan dan prosedur kerja 
Farida. Implementasi Perkuliahan daring matakuliah.....

untuk kegiatan praktikum minggu depan. Media online memang sangat beragam dengan berbagai manfaatnya masing-masing. Pemilihan media online tidak serta merta karena kepentingan dosen semata namun harus disesuaikan juga dengan kemampuan tiap mahasiswanya (Pratiwi, 2020). Media online yang dipergunakan selama perkuliahan daring harus dipertimbangkan dari segi kebermanfaatan, kemudahan akses dan segi nilai ekonomis para mahasiswa (Anhusadar, 2020).

\section{Tahap Pemberian Tugas Terstruktur}

Tugas terstruktur yang diberikan berupa laporan kegiatan praktikum. Tugas diberikan sama dengan tugas ketika perkuliahan tatap muka. Untuk mengerjakan laporan mahasiswa membagi sendiri tugas masing-masing individu melalu WAG satu kelompok itu sendiri. Sebagai monitoring tiap bagian siapa saja yang mengerjakan, tiap kelompok wajib mencantumkan bagian tugas masing-masing individu dibagian akhir laporan. Hal tersebut bertujuan untuk mempertanggung jawabkan apa yang sudah dikerjakan. Serta sebagai bahan refleksi kelompok jika bagian tersebut mendapatkan nilai yang rendah. Laporan praktikum diupload pada link google drive seminggu setelah jadwal daring berlangsung atau pada saat jadwal daring berikutnya.

Pemberian tugas berupa laporan praktikum memang menjadi tugas wajib bagi mahasiswa yang menempuh matakuliah Pendidikan Laboratorium IPA. Tugas laporan ini mendapatkan nilai yang tinggi karena dasar pengerjaan laopran yang cukup menguras waktu dan tenaga. Perbedaan laporan kegiatan praktikum pada saat tatap muka dan pada saat daring selama masa pandemic ini adalah dari segi tekni pelaksanaanya saja. Ketika perkuliahan tatap muka laopran praktikum wajib ditulis tangan, sedangkan ketika perkuliahan daring laporan diketik menggunakan Ms Word dikarenakan adanya himbauan untuk SFH (Study From Home) oleh pemerintah. Meskipun laporan praktikum bersifat wajib bagi mahasiswa, namun untuk pengerjaan praktikum perlu kesepakatan dengan mahasiswa pada saat kontrak kuliah. Kesepakatan bersama perlu diambil agar tidak ada pernyataan yang memberatkan ketika mengerjakan laporan praktikum (Rahayu \& Eliyarti, 2019)

\section{SIMPULAN}

Pelaksanaan perkuliahan daring pada matakuliah Pendidikan Laboratorium IPA pada masa pandemi terdiri atas 3 tahap yang berasal dari modifiaksi perkuliahan tatap 
Farida. Implementasi Perkuliahan daring matakuliah.....

muka yakni tahap persiapan yang didalamnya berisi menyiapkan video penguatan alat, bahan dan prosedur kerja praktikum yang kemudian dishare melalu WAG pada masingmasing kelas. Berikutnya tahap pelaksanaan, pada tahap ini merupakan pelaksaan perkuliahan daring sesuai jadwal perkuliahan tatap muka. Pada pelaksnaan perkuliahan daring dosen memandu mahasiswa untuk melakukan presensi, upload laporan praktikum, memberikan link google drive, upload bukti kegiatan praktikum, memberikan pertanyaan diskusi, menjawab, menanggapi dan meluruskan hasil diskusi, menyimpulkan hasil diskusi dan menutup perkuliahan. Tahap terakhir yaitu tahap pemberian tugas berupa laporan hasil kegiatan praktikum yang dikerjakan perkelompok dikumpulkan pada saat jadwal perkuliahan daring berikutnya. Perkuliahan daring ini didukung oleh media online berupa video, WAG dan google drive.

\section{UCAPAN TERIMA KASIH}

Ucapan terima kasih kepada semua pihak yang telah membantu kelancaran penelitian ini terutama untuk mahasiswa PGSD Universitas Nusantara PGRI Kediri semester 4 yang menempuh matakuliah Pendidikan Laboratorium IPA. Mahasiswa kelas 2C dan 2D yang sangat responsive dan respect serta mampu diajak kerjasama dengan baik selama perkuliahan daring berlangsung

\section{DAFTAR RUJUKAN}

Anhusadar, L. O. (2020). Persepsi Mahasiswa PIAUD terhadap Kuliah Online di Masa Pandemi. KINDERGARTEN: Journal of Islamic Early Childhood Education, 3(1), 44-58.

https://www.researchgate.net/publication/341151841_Persepsi_Mahasiswa_PIAU

D_terhadap_Kuliah_Online_di_Masa_Pandemi_Covid_19

Iwantara, I., Sadia, M., \& Suma, M. (2014). Pengaruh Penggunaan Media Video Youtube Dalam Pembelajaran Ipa Terhadap Motivasi Belajar Dan Pemahaman Konsep Siswa. Jurnal Pendidikan Dan Pembelajaran IPA Indonesia, 4(1). http://119.252.161.254/e-journal/index.php/jurnal_ipa/article/view/1081/829

Jamaluddin, D., Ratnasih, T., Gunawan, H., \& Paujiah, E. (2020). Pembelajaran Daring Masa Pandemik Covid-19 Pada Calon Guru: Hambatan, Solusi dan Proyeksi. Karya Tulis Ilmiah UIN Sunan Gunung Djjati Bandung, 1-10. http://digilib.uinsgd.ac.id/30518/

Khasanah, D. R. A. U., Pramudibyanto, H., \& Widuroyekti, B. (2020). Pendidikan Dalam Masa Pandemi Covid-19. Jurnal Sinestesia, 10(1), 41-48. 
Farida. Implementasi Perkuliahan daring matakuliah.....

kompas. (2014). Pemanfaatan Internet Sebagai Alternatif Sumber Belajar Dan Media Pendidikan Jarak Jauh - KOMPASIANA.com. Kompasiana. http://www.kompasiana.com/hariyono21/pemanfaatan-internet-sebagai-alternatifsumber-belajar-dan-media-pendidikan-jarak-jauh_55003ff4a33311c271510187

Naserly, M. K. (2020). Implementasi Zoom, Google Classroom, Dan Whatsapp (Online), Group Dalam Mendukung Pembelajaran Daring 2, Pada Mata Kuliah Bahasa Inggris Lanjut (Studi Kasus Pada 2, Kelas Semester Jurusan Administrasi Bisnis, Fakultas Ekonomi dan Bisnis Jakarta), Universi. Jurnal AKSARA PUBLIC, 4(2), 155-165. http://aksarapublic.com/index.php/home/article/view/417/402

Pratiwi, E. W. (2020). Dampak Covid-19 Terhadap Kegiatan Pembelajaran Online Di Sebuah Perguruan Tinggi Kristen Di Indonesia. Perspektif Ilmu Pendidikan, 34(1), 1-8. https://doi.org/doi.org/10.21009/PIP.341.1 Volume

Primavera, I. R. C., \& Iwan Permana Suwarna, M. P. (2014). Pengaruh Media Audio Visual Terhadap Hasil Belajar Siswa Kelas XI Pada Konsep Elastisitas. Prosiding Seminar Nasional Pendidikan IPA FITK UIN Syarif Hidayatullah Jakarta, 1, 122129.

Rahayu, C., \& Eliyarti, E. (2019). Deskripsi Efektivitas Kegiatan Praktikum Dalam Perkuliahan Kimia Dasar Mahasiswa Teknik. Edu Sains Jurnal Pendidikan Sains \& Matematika, 7(2), 51-60. https://doi.org/10.23971/eds.v7i2.1476

Safrida, F. K. (2018). Pengaruh Penggunaan Media Video pada Konsep Sistem Kerangka Manusia terhadap Motivasi dan Hasil Pembelajaran Kognitif Siswa SMAN I Peukan Baru Kabupaten Pidie. Jurnal Biotik, 6(2), 131-138. https://www.jurnal.ar-raniry.ac.id/index.php/biotik/article/view/5636/3587

Saida, N. U., Iswari, R. S., \& Pukan, K. K. (2018). Penerapan Metode Praktikum dan Simulasi pada Materi Ekosistem di SMA Negeri 2 Bae Kudus. Journal of Biology Education, 7(2), 216-220. https://doi.org/10.15294/jbe.v7i2.24263

Suja, I. W., \& Muderawan, I. W. (2003). Pemberian Tugas Pertanyaan Berstruktur Dan Diskusi Untuk Meningkatkan Kualitas Praktikum Kimia Organik II. Jurnal Pendidikan Dan Pengajaran IKIP. 